\title{
Gillnet Mesh Selectivity for the Shovelnose Guitarfish (Rhinobatos productus) from Fishery-Dependent Data in the Artisanal Ray Fishery of the Gulf of California, Mexico
}

\author{
J. Fernando Márquez-Farias ${ }^{1}$ \\ Centro Regional de Investigación Pesquera de Guaymas, Instituto Nacional de la Pesca SAGARPA \\ Calle 20 Sur No. 605. Col. Cantera, CP8 85400, Guaymas, Sonora, Mexico
}

\begin{abstract}
Márquez-Farias, J. F. 2005. Gillnet Mesh Selectivity for the Shovelnose Guitarfish (Rhinobatos productus) from Fishery-Dependent Data in the Artisanal Ray Fishery of the Gulf of California, Mexico. J. Northw. Atl. Fish. Sci., 35: 443-452. doi:10.2960/J.v35.m505
\end{abstract}

\begin{abstract}
The Gulf of California supports the largest ray fishery in Mexico. Sonora is a major ray-fishing state, reporting 56\% (live weight) of the Pacific Ocean rays production. Bottom-set gillnets are the principal fishing gear deployed in this artisanal fishery. In the absence of long-term monitoring and complex biological data for fishery stock assessment, an understanding of the selectivity properties of gillnets can provide a basis for implementation of a standard mesh-size as regulation tool for fishery management. Ideally, gillnet selectivity parameters are determined from fishing trials with several gillnets of a range of mesh-sizes constructed and used in a way to control for factors likely to affect the fishing power nets. In the absence of such experimental data, the present study uses available fishery-dependent monitoring data standardized to construct a data set that meets as near as possible the conditions met in a controlled experiment. A likelihood-based method was used to estimate the selectivity parameters for the shovelnose guitarfish (Rhinobatos productus) caught in the Gulf of California. The values of the selectivity parameters were $\theta_{1}=105.7$ and $\theta_{2}=21741$ for $3.5,5,6,8$, and 8.5 inch mesh sizes.
\end{abstract}

Key words: artisanal fisheries, elasmobranchs, gear selectivity, gillnet, rays, regulation

\section{Introduction}

The artisanal ray fishery in the Gulf of California operates in the coastal waters of the Mexican states of Sinaloa, Sonora, Baja California Norte and Baja California Sur (Fig. 1). Like other artisanal fisheries in Mexico, the ray fishery in Sonora is part of a multispecies fishery that is an important source of food and employment for fishing communities in the region. At least 21 species of rays are captured in the fishery depending on seasonal abundance of the key species. In 1999, the total catch of rays reported from Sonora was 2757 tons $(30 \%$ of ray catch of Mexico and $56 \%$ of the ray catch of the west coast of Mexico) (Anon., 2000).

During a 2-year elasmobranch survey undertaken in Sonora (1998-99), 45 species of elasmobranchs were recorded (Hueter et al., 2000). Almost half of these were a diverse range of rays ( 9 sub-orders, 4 families, and 21 species). Most of the rays belonged to the sub-order Rhinobatoidae, family Rhinobatidae $(46.9 \%, n=95346)$, with the shovelnose guitarfish (Rhinobatos productus) being the most abundant species by number (40.2\%) (MárquezFarias et al., 1999).
In the Gulf of California, R. productus is an important by-catch species in the trawl shrimp fishery, which produces about half of Mexico's shrimp catch. Based on a $1: 10$ average shrimp to by-catch ratio (by mass), it is estimated that the shrimp fishery by-catch in 1996 was nearly 200000 tons, including more than 100 fish species and 114 invertebrate species (García-Caudillo et al., 2000). An evaluation of the effectiveness of by-catch reduction devices (BRD) by the Instituto Nacional de la Pesca provided encouraging results. The mean exclusion rates for a number of species in the families Balistidae, Serranidae, Lutjanidae, Sciaenidae, Paralichthydae, Batrachoididae, Scorpaenidae, Synodontidae and Rhinobatidae were markedly reduced. $R$. productus had a mean exclusion rate of 37\% (García-Caudillo et al., 2000). The high exploitation of ray stocks in the Gulf of California and the increasing need for regulation of the fishery has prompted the need to determine the selectivity properties of gillnets used in the artisanal ray fishery. Apart from the immediate need for gear regulation, knowledge of the selectivity properties is essential for future stock assessment.

The purpose of the present study is to estimate the gillnet mesh selectivity parameter values for $R$. productus

\footnotetext{
1 Centro Regional de Investigación Pesquera de Mazatián, Instituto Nacional de la Pesca SAGARPA, Calzada Sábalo-Cerritos S/N,
} CP. 82010, Mazatlan, Sinaloa, Mexico 


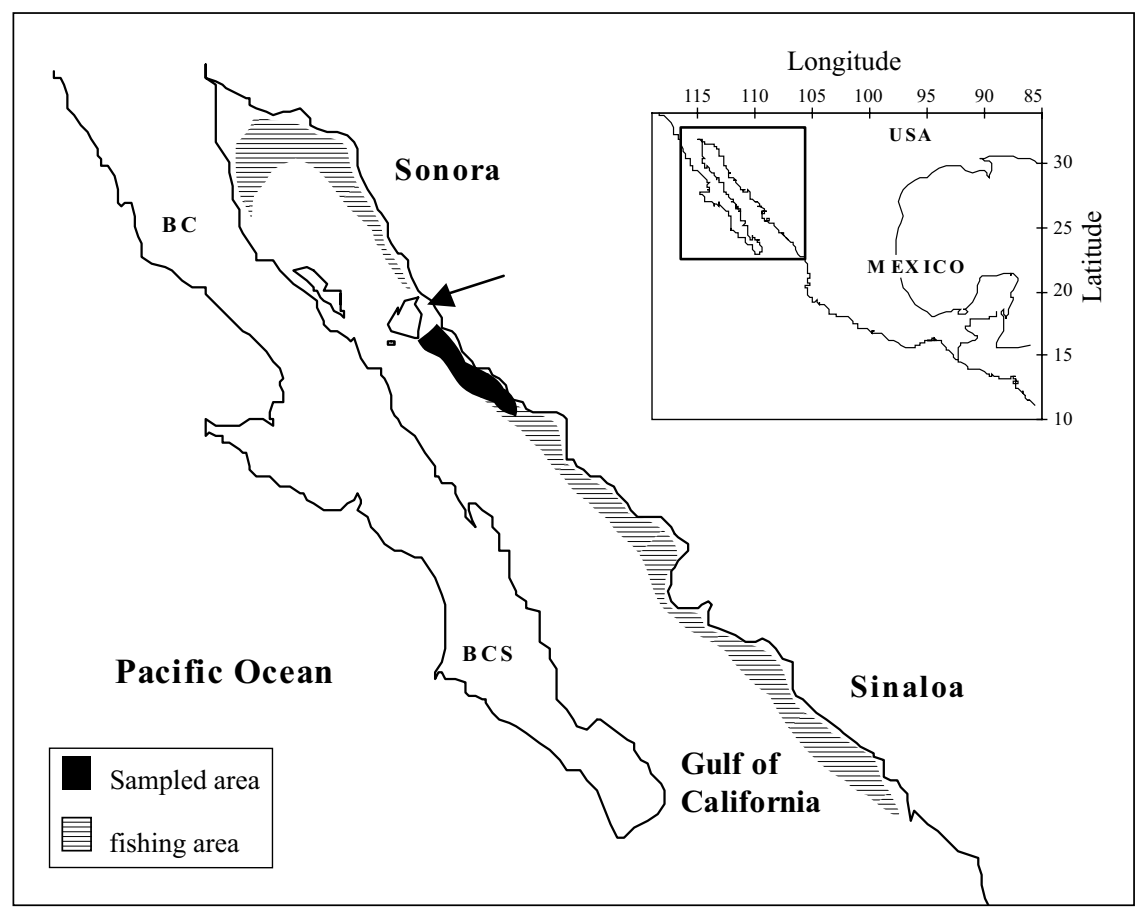

Fig. 1. Dashed area shows the fishing area of the artisanal ray fishery of the Gulf of California. Black shading is location where the analyzed data were collected. Arrow indicates Canal del Infiernillo (see text) located between main land and Isla Tiburón.

by adopting a model originally developed for analyzing experimental data for gummy shark (Mustelus antarcticus) in south-eastern Australia (Kirkwood and Walker, 1986). The present study uses available fishery-dependent data sets in a way to avoid departing from the assumptions underlying the experimental approach adopted for M. antarcticus.

\section{Materials and Methods}

\section{Model for estimation of gillnet selectivity}

The model developed by Kirkwood and Walker (1986) is a flexible, two-parameter model for determining relative selectivity that can account for varying amounts of right skew of data. The model is derived from the probability density function of a gamma distribution with parameters $\alpha$ and $\beta$ and argument $x$ and has the probability density

$$
\left[x^{\alpha} \exp (-x / \beta) / \Gamma(a+1)\right] / \beta^{(\alpha+1)}
$$

with a single mode at $x=\alpha \beta$ and variance $(\alpha+1) \beta^{2}$. In this expression, $\Gamma($.$) is the standard gamma function.$

Briefly summarizing Kirkwood and Walker (1986), $m_{i}$ is mesh-size of gillnet $i(i=1,2, \ldots, I) ; l_{j}$ is the mid- length of length-class $j(j=1,2, \ldots, J)$; $n_{i j}$ is the number of fish of length-class $j$ caught by net $i ; \mu_{j}$ is the proportional number of fish in the sample of length-class $j ; S_{i j}$ is the mean relative selectivity of net $i$ for fish of length-class $j$; and $f_{i}$ is fishing power at the size of maximum selectivity, relative to the maximum power over all $I$ nets. For suitably scaled $\mu_{j}$,

where

$$
\begin{gathered}
n_{i j}=f_{i} \mu_{j} S_{i j} \\
\mu_{j}=\left(\frac{\sum_{i=1}^{I} n_{i j}}{\sum_{i=1}^{I} S_{i j}}\right)
\end{gathered}
$$

The selectivities $S_{i j}$, can be modeled by simple functions of $m_{i}$ and $l_{j}$. The mode and variance of the probability density function are taken to be functions of $m_{i}$ and $l_{j}$. For each gillnet $i$ and length-class $j$, the catches $n_{i j}$ are independent observations from a Poisson distribution with mean $\mu S_{i j}$. To model relative selectivity, $S_{i j}$ with a maximum of one, is re-scaled so that the modal value is one. The functional form used to model the selectivities as a function of length, $l_{j}$, and mesh-size, $m_{i}$, is

$$
S_{i j}=\left(\frac{I_{j}}{\alpha_{i} \beta_{i}}\right)^{\alpha i} \exp \left(\alpha_{i}-\frac{I_{j}}{\beta_{i}}\right)
$$


where $\alpha_{i}$ and $\beta_{i}$ are specified in terms of the mesh-size, $m_{i}$, and length-class, $l_{j}$, and the length at maximum selectivity for gillnet $i$ is proportional to the mesh-size such that

$$
\alpha_{i} \beta_{i}=\theta_{1} m_{i}
$$

and the variance $\left(\theta_{2}\right)$ is a constant over different gillnets. These assumptions lead to a quadratic equation for positive $\beta_{i}$ such that

$$
\beta_{i}=-0.5\left[\theta_{1} m_{i}-\left(\theta_{1}^{2} m_{i}^{2}+4 \theta_{2}\right)^{0.5}\right]
$$

The log-likelihood for the data set is given by

$$
L=\sum_{i=1}^{I} \sum_{j=1}^{J}\left[n_{i j} \ln \left(\mu_{j} S_{i j}\right)-\mu_{j} S_{i j}\right]
$$

The likelihood function to estimate the values of $\theta_{1}$ and $\theta_{2}$ was maximized with the aid of the optimization function of the commercial software Microsoft Excel Ver 7.0.

The $95 \%$ confidence interval for each of $\theta_{1}$ and $\theta_{2}$ was estimated according to Venzon and Moolgavkar (1988). The confidence intervals are based on $\chi^{2}$ distribution with $d$ degrees of freedom. For a single parameter, the confidence bound is defined as all values of $p$ that satisfy the equation

$$
\mathrm{Cl}_{95 \%}=2\left[L(\mathrm{Y} \mid \mathrm{p}=p)-L\left(\mathrm{Y} \mid \mathrm{p}=p_{\text {est }}\right)=\chi_{1,1-\alpha}^{2}\right]
$$

where $L(\mathrm{Y} \mid \mathrm{p}=b)$ is the negative log-likelihood corresponding to the maximum likelihood estimates, $L\left(\mathrm{Y} \mid \mathrm{p}=b_{\text {est }}\right)$ is the lowest negative log-likelihood possible when $\mathrm{p}$ is set to $p$ (minimizing the negative of loglikelihood function subject to the constrains that $\mathrm{p}=p$ ), and $\chi_{1,1-\alpha}^{2}$ is the value of the $\chi^{2}$ distribution with 1 degree of freedom at confidence level $1-\alpha$.

Assumptions about the nets of different mesh-size were necessary to apply the model to fishery-dependent data. (1) The nets were set in the same general region. (2) The nets were cleared of catch each day to avoid loss of catch from predation. (3) The nets had comparable height, and the height of the nets were not affected by the catch; rays tend to be captured at the bottom of the nets because of their demersal habits. (4) The nets had similar length. (5) The nets had similar fishing times. (6) Targeting by fishers was independent of mesh-size. The essence of these assumptions is that fishing power is constant across nets of all mesh-sizes and that all nets are operating on the same population of fish.

\section{Data collection}

Data from the fishery for application in the model for estimating the selectivity parameters were collected during the period from May 1998 to November 1999 in the main elasmobranch fishing camps of Sonora (Fig. 1). Total length of R. productus was measured as the straightline distance from the tip of the snout to the distal end of the caudal fin. In addition, for a sample of animals, disc width was measured as the straight-line distance from the left margin of the disc (tip of the left pectoral fin) to the right margin of the disc (tip of the right pectoral fin). Details of fishing effort (soak time, depth and locality of fishing) and gear characteristics (mesh-size, length and height of each net) were obtained by interviewing fishers at the end of each fishing trip.

Mesh-size of the bottom-set gillnets deployed in the artisanal fishery ranged 3.5-10.0 inches. Only gillnets constructed from green or pink monofilament polyamide webbing of mesh size 3.5-8.5 inch were included in the analyses for the present study. Available data from 10 inch mesh size (commonly used for targeting large rays) were excluded from the analysis because they were constructed from multifilament webbing. Height of the nets varied slightly with mesh size. Length of the nets ranged 800-2 $000 \mathrm{~m}$, fishing period varied 12-36 hr, with $12 \mathrm{hr}$ being the most common, and fishing depth varied 5-72 $\mathrm{m}$ (1-30 km from the fishing camps). The nets were set with an anchor-weight and buoy-line attached to each end.

\section{Data analysis}

The data available for analysis for mesh-sizes (3.5, $5,6,8$ and 8.5 inches) were initially treated in two steps for each mesh-size separately. The first step was to weight up the sample length-frequency distribution expressed in $50 \mathrm{~mm}$ length-classes to the total number caught over all vessel-trips to produce a length-frequency distribution for the entire catch. The second step was to weight the length-frequency distribution for the entire catch by a standardization factor (SF) where $\mathrm{SF}=10 /$ number of vessel trips. Differences in fishing power of gillnets are reduced by using a $\mathrm{SF}$ of the catch rate.

For each mesh-size separately, the frequency of total length measurements of sampled rays were tabulated within $50 \mathrm{~mm}$ length-classes and then weighted to the total number of landed rays. The weighted length-frequency distribution for the entire catch was further weighted by a SF to provide the number caught in each $50 \mathrm{~mm}$ lengthclass per 10 vessel-trips. For each mesh-size, $\mathrm{SF}=10$ 
vessel-trips/total number of vessel trips. This provided the number of sharks per 10 vessel-trips within each 50 $\mathrm{mm}$ length-class standardized across all mesh-sizes. The standardized data for $R$. productus was then analyzed to estimate the selectivity parameters $\theta_{1}$ and $\theta_{2}$.

\section{Results}

Rhinobatos productus provided $75.8 \%$ of the catch by number for the period considered by the present study. A catch of 4510 animals of this species was recorded from 474 vessel-trips, of which 598 animals were measured. The 6 inch mesh-size, which was used during 35.7\% of the vessel-trips in which rays were landed, caught $54.1 \%$ of the number of $R$. productus included in the analysis. The number of $R$. productus sampled in each $50 \mathrm{~mm}$ length-class and the computed SF are presented in Table 1. Catches were comparable between the mesh sizes, with the exception of the 3.5-inch mesh-size, which had the lowest catch (Table 2).

The assumption that total length (TL) at maximum selectivity is proportional to the mesh size is validated by the strong linear relationship between disc width (DW) and TL for the two sexes combined as DW $=2.7577 \times \mathrm{TL}$ $+4.3582\left(r^{2}=0.962, n=232\right)$. The implicit assumption here being that DW determines how effectively a ray is enmeshed.

TABLE 1. Number of rays measured and counted, number of vessels trip counted and calculated standardization factor (SF) for each mesh-size

\begin{tabular}{|c|c|c|c|c|c|c|}
\hline \multirow[b]{2}{*}{ Variable } & \multicolumn{5}{|c|}{ Number measured for each mesh-size (inches) } & \multirow[b]{2}{*}{ Total } \\
\hline & 3.5 & 5.0 & 6.0 & 8.0 & 8.5 & \\
\hline Rays measured & 35 & 99 & 189 & 129 & 146 & 598 \\
\hline Rays counted & 90 & 1061 & 2442 & 330 & 587 & 4510 \\
\hline $\begin{array}{l}\text { Successful vessel-trips } \\
\text { taking any species of ray }\end{array}$ & 13 & 37 & 132 & 169 & 123 & 474 \\
\hline $\begin{array}{l}\text { Standardization factor }{ }^{2} \\
\text { (Number of rays per } 10 \text { vessel-trips) }\end{array}$ & 1.98 & 2.90 & 0.98 & 0.15 & 0.33 & 6.33 \\
\hline
\end{tabular}

1 Zero catch not included

2 Number measured/Number of vessel trips.

TABLE 2. Number of Rhinobatos productus measured in each $50 \mathrm{~mm}$ length-class for each gillnet mesh-size used in the artisanal ray fishery of Sonora. SF $=$ Standardization factor.

\begin{tabular}{|c|c|c|c|c|c|c|}
\hline \multirow{2}{*}{$\begin{array}{c}\text { Length-class } \\
(\mathrm{mm})\end{array}$} & \multicolumn{5}{|c|}{ Mesh-size (inches) } & \multirow[b]{2}{*}{ Tota } \\
\hline & 3.5 & 5 & 6 & 8 & 8.5 & \\
\hline $250-299$ & 1 & & & & & 1 \\
\hline $300-349$ & 3 & & & & & 3 \\
\hline $350-399$ & & & & & & \\
\hline $400-449$ & 3 & 4 & 1 & 1 & 1 & 10 \\
\hline $450-499$ & 11 & 3 & 5 & 3 & 2 & 24 \\
\hline $500-549$ & 10 & 24 & 29 & 21 & 20 & 104 \\
\hline $550-599$ & 4 & 50 & 44 & 22 & 23 & 143 \\
\hline $600-649$ & 1 & 17 & 40 & 21 & 27 & 106 \\
\hline $650-699$ & & 1 & 33 & 15 & 24 & 73 \\
\hline $700-749$ & & & 10 & 8 & 16 & 34 \\
\hline $750-799$ & & & 14 & 22 & 15 & 51 \\
\hline $800-849$ & 2 & & 9 & 7 & 14 & 32 \\
\hline $850-899$ & & & 4 & 9 & 3 & 16 \\
\hline $900-949$ & & & & & 1 & 1 \\
\hline Total & 35 & 99 & 189 & 129 & 146 & 598 \\
\hline SF & 1.98 & 2.90 & 0.98 & 0.15 & 0.33 & \\
\hline
\end{tabular}


The length-frequency distribution obtained for each mesh-size could be influenced by the spatial and temporal distribution of rays. As noted by Kirkwood and Walker (1986), aggregation of fish by size-class has implications for the assumption that individual catches are independently Poisson-distributed. Aggregation might account for the peak observed in the length-frequency distribution for 8-inch mesh-size (Fig. 2). This observation is consistent
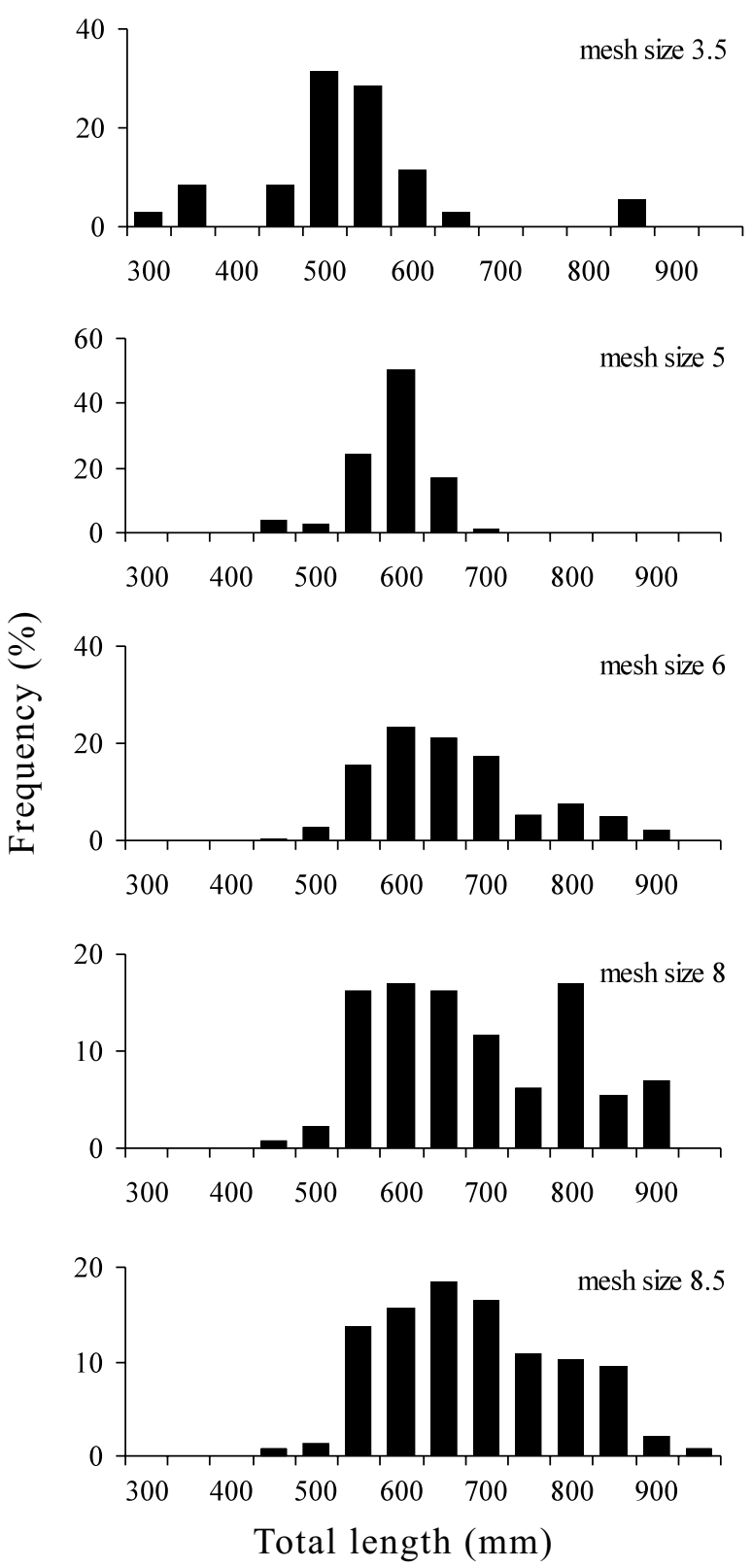

Fig. 2. Total length-frequency distribution (\%) for $R$. productus caught in the artisanal ray fishery of Sonora for gillnets with 3.5, 5, 6, 8 and 8.5 inch mesh-size. with the assumption adopted by those authors that the selectivity function follows the gamma distribution to account for the tendency of large individuals to be entangled. Table 3 shows the number of rays per 10 vessel-trips within 50-mm length-classes for each mesh-size.

The estimated values with $95 \%$ confidence range (CI) of the selectivity parameters were $\theta_{1}=105.7$ $(\mathrm{CI}=103-107), \theta_{2}=21741$ (CI = 19 900-25 200). The residuals indicate variable fit performance for the various mesh-sizes and length-classes (Fig. 3). The plots of normalized residuals show that the data fit better for the 5, 6 and 8 inch mesh-sizes than for the 3.5 and 8.5 inch mesh-sizes. A family of curves represents the estimated relative selectivity of commercial gillnets (Fig. 4). As expected the size of maximum selectivity $(\sim 1.0)$ increases with mesh-size.

\section{Discussion}

Few selectivity estimates have been made for elasmobranchs and those that have all been made were for sharks (Kirkwood and Walker, 1986; McLoughlin and Stevens, 1994; Walker, 1997; Simpfendorfer and Unsworth, 1998; Carlson and Cortés, 2003). These studies were all based on experimental research closely matching the standard gears used in the respective fisheries.

Sonora's artisanal elasmobranch fisheries are typically based on multispecies assemblages, they lack adequate

TABLE 3. Number of Rhinobatos productus captured per 10 vessel-trips in each $50 \mathrm{~mm}$ length-classes for each mesh-size.

\begin{tabular}{ccccccc}
\hline \hline $\begin{array}{c}\text { Length-class } \\
(\mathrm{mm})\end{array}$ & \multicolumn{5}{c}{ Mesh-size (inches) } & \\
\cline { 2 - 5 } & 3.5 & 5 & 6 & 8 & 8.5 & Total \\
\hline $250-299$ & 2.0 & & & & & 2.0 \\
$300-349$ & 5.9 & & & & & 5.9 \\
$350-399$ & & & & & & \\
$400-449$ & 5.9 & 11.6 & 1.0 & 0.2 & 0.3 & 19.0 \\
$450-499$ & 21.8 & 8.7 & 4.9 & 0.5 & 0.7 & 36.4 \\
$500-549$ & 19.8 & 69.5 & 28.4 & 3.2 & 6.5 & 127.4 \\
$550-599$ & 7.9 & 144.8 & 43.1 & 3.3 & 7.5 & 206.7 \\
$600-649$ & 2.0 & 49.2 & 39.2 & 3.2 & 8.8 & 102.4 \\
$650-699$ & & 2.9 & 32.3 & 2.3 & 7.8 & 45.3 \\
$700-749$ & & & 9.8 & 1.2 & 5.2 & 16.2 \\
$750-799$ & & & 13.7 & 3.3 & 4.9 & 21.9 \\
$800-849$ & 4.0 & & 8.8 & 1.1 & 4.6 & 18.4 \\
$850-899$ & & & 3.9 & 1.4 & 1.0 & 6.3 \\
$900-949$ & & & & & 0.3 & 0.3 \\
\hline
\end{tabular}



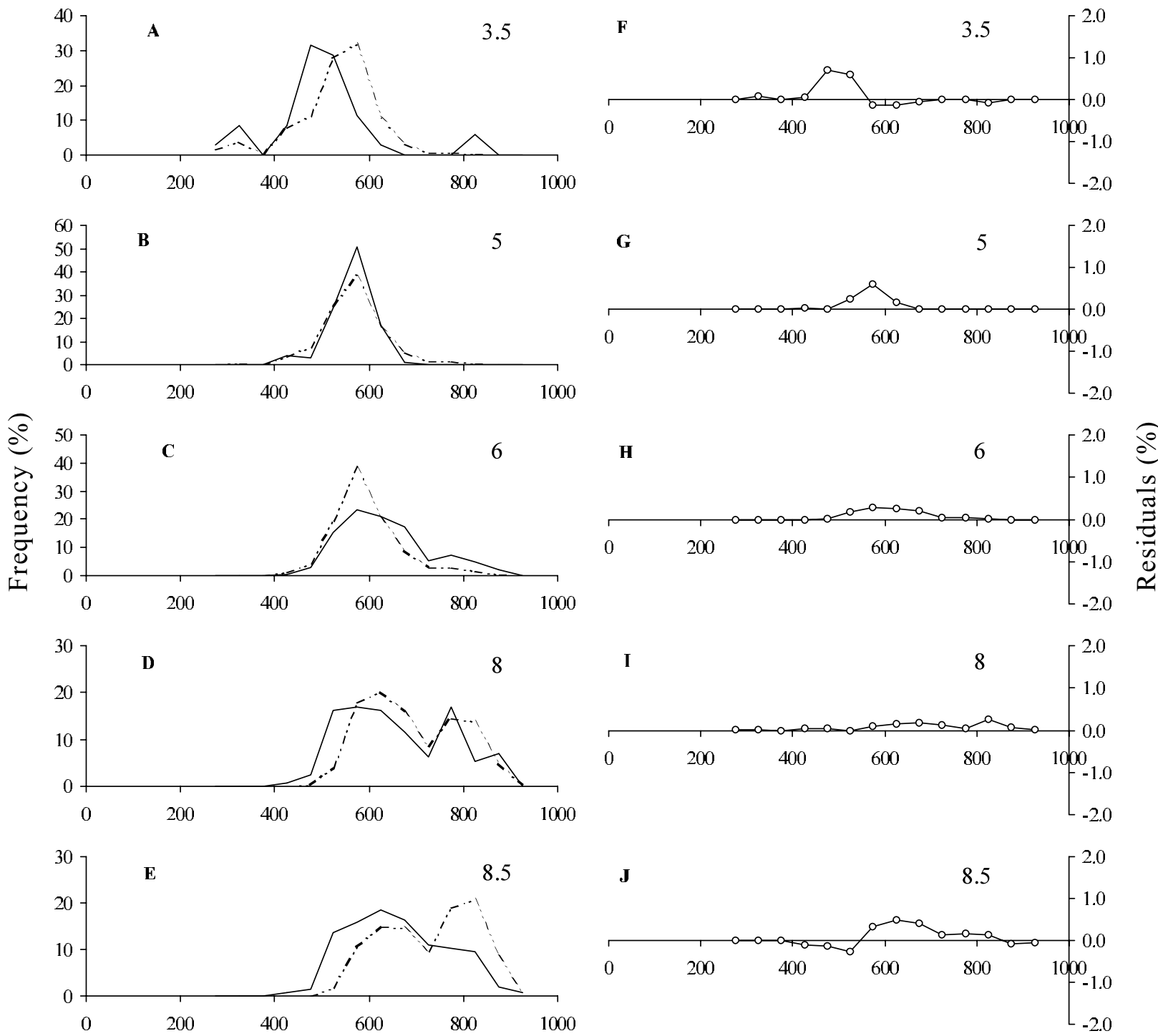

Total length $(\mathrm{mm})$

Fig. 3. Observed versus predicted length-frequency distribution resulting from the fitted model (A-E) and normalized (\%) residuals of the log-likelihood by total length $(\mathbf{F}-\mathbf{J})$.

fisheries research and monitoring, and, until recently, they have received low research priority. For such fisheries, selectivity estimation can be undertaken by regular sampling of landings in coastal fishing camps. Analysis of data derived directly from the landing place creates uncertainty, because discarding at sea is a potential source of bias. In general, small animals are more likely than large animals to be discarded at sea and resulting in an under representation of the frequency of small size-classes, but this is considered negligible for $R$. productus.
In the present study, selectivity was defined in terms of those animals actually encountering the net, rather than in terms of the whole population as considered by Kirkwood and Walker (1986). As these authors pointed out, there is a higher availability of the population in time and space to the fishing gear used in the actual fishery compared with that during a short-term experiment. When analysis is based on data derived from experimental gillnetting or from on-board monitoring of fishing activities, it is possible to discriminate between those animals 


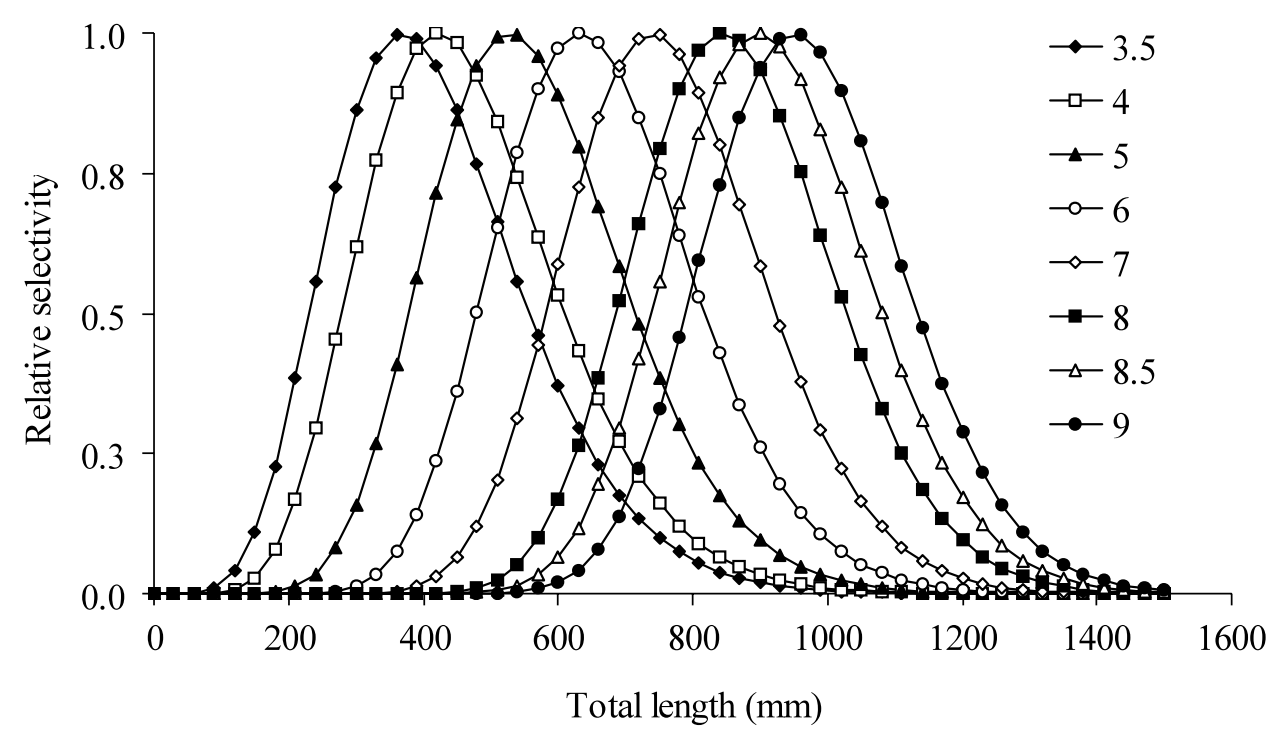

Fig. 4. Family of curves of relative selectivity applying the Kirkwood and Walker (1986) model to $R$. productus taken in the artisanal ray fishery of Sonora.

enmeshed and those entangled (McLoughlin and Stevens, 1994; Simpfendorfer and Unsworth, 1998). In the present study, it was accepted that the catch of $R$. productus in commercial fisheries includes randomly entangled large animals in addition to the enmeshed animals (McLoughlin and Stevens, 1994).

Several factors might have contributed to catch efficiency by size of animal to cause some departure from the model assumption of similar fishing power of nets across all mesh-sizes. 1) Morphology of $R$. productus with its pointed-shape of head with large pliable pectoral fins affects escapement. For example, when animals encounter the net, small individuals are more likely to escape than large animals because the margins on both sides of their disc bend. In large animals, although the pectoral fins bend, the body does not readily penetrate through the meshes. 2) Seasonal migration from shallow to deep waters for reproductive purposes and aggregation by sex and size (personal observation) could cause potential biases in the analyses. 3) Oceanographic currents sometimes drag the nets and, depending on current strength, can distort the shape of the meshes and hence affect the effective mesh-size. This is particularly true for the fishing ground located close to Canal del Infiernillo (Little Hell Channel) between Isla Tiburón (Shark Island) and the mainland, where the water currents are particularly strong at times (Fig. 1). 4) The technical properties of the net can vary when fishers modify their gear to specifically target valuable fish such as flounder by attaching suspenders in different sections of the gear. This modification results in the net being moved by the water current and the formation of bags where animals can be more easily entangled.

Another factor that could affect the values of the selectivity parameter estimates is that trips with zero catches were not sampled. This bias is negligible for the present-study because landings with zero catch of elasmobranch animals are rare. Gear saturation could affect the results, but this effect is also considered negligible for the present study.

The effect of the size-class interval on the parameter estimates was explored. Increasing the length-class interval from 20 to $100 \mathrm{~mm}$ in steps of $10 \mathrm{~mm}$ produced a mean value of $\theta_{1}=105.73(\min =105.54, \max =106.31$, $\pm 0.16, \alpha=0.05)$ and of $\theta_{2}=22069(\mathrm{~min}=21387, \max$ $=23883, \pm 507, \alpha=0.05)$. As expected, the likelihood resulting from this manipulation increased exponentially as the intervals increased. The range of these possible input values to estimate the selectivity parameters is especially relevant for future parameter estimates, particularly as optimizing techniques are highly dependent on good starting values. Previous estimates of the parameter could help to define prior probabilities of the parameter in a Bayesian framework (Gelman et al., 1995) taking advantage of the convenient model-induced likelihood methods as the one used here (Millar, 2000). The reasoning behind the Bayesian approach is, however, beyond the scope of the present study. 


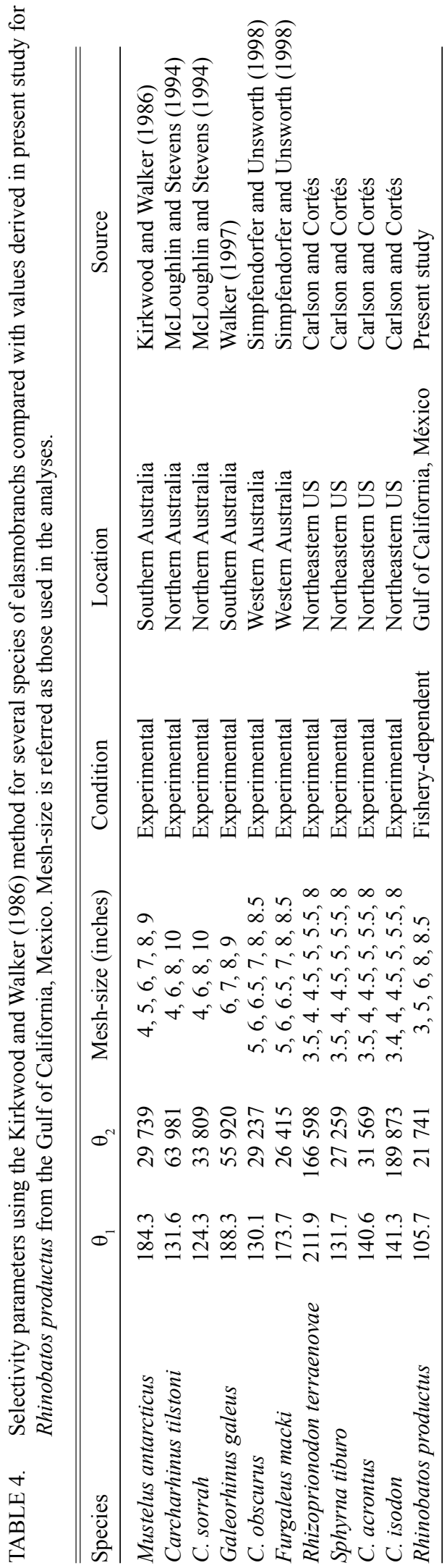


It is difficult to compare the results from the present study with published values of $\theta_{1}$ and $\theta_{2}$ because there have been no previous attempts to estimate selectivity parameters for rays. The estimates of selectivity parameters derived in present study are out of the range of values derived for other elasmobranchs (Table 4). Walker et al. (1998) observed that small sharks swim through gillnets and they become increasingly vulnerable to capture as they grow until they reach a size of maximum selectivity, after which size they become progressively less vulnerable. This is true for fusiform-shaped organisms such as Mustelus antarcticus, but less evident for dorsoventrally flattened species such as $R$. productus, $R$. glaucostigma, Zapterix exasperata and Narcine entemedor, which are harvested in the artisanal ray fishery in the Gulf of California. Among these dorsoventrally flattened species, fitting the selectivity model to a gamma distribution is considered acceptable for species like Rhinobatos sp. and Narcine $\mathrm{sp}$; it would be valuable to test the model's performance in species such as Dasyatis brevis. The rounded shape of this ray is likely to produce particularly wide selectivity curves (i.e. high $\theta_{2}$ values).

Estimation of selectivity parameters when data on reproduction are available is essential to assess vulnerability to capture at each life history stage for harvested species. The studies available on the demography of elasmobranchs assume fishing mortality to be constant with age and to be knife-edge between pre-recruit and recruited animals. This is because of the lack of selectivity estimates for the associated fisheries (Cailliet, 1992; Cortés, 1998; Sminkey and Musick, 1996). Au and Smith (1997) developed a demographic method for estimating the productivity of sharks and recognized the need for specifying the mortality schedule affecting the age structure of a population affected by highly selective gears. Consideration of the effect of gear selectivity when estimating demographic parameters may reveal a greater resilience of some elasmobranch species than previously thought. Walker (1998) noted that demographic characteristics of the gummy shark, which incorporated the effect of gillnet selectivities and natural mortality across age-classes, provided a more optimistic prognosis of the stock than previous assessments that had not included gear selectivity.

The length-based, highly selective nature of gillnets suggests that care must be taken when interpreting catch data (Kirkwood and Walker, 1986). Of particular importance is the identification of factors influencing the catch process for fishery dependent analyses. Most of the factors listed above are applicable to other artisanal fisheries and should be considered when fitting the model to the data.
The results from the present study will become more relevant for regulation of the ray fishery of the Gulf of California when their reproduction is better understood.

\section{Acknowledgements}

Several people are thanked for their contributions. Rachael Bathgate is thanked for her assistance in translating an early draft of the manuscript. Miguel Cisneros is thanked for his comments on an early draft of the manuscript. Terry Walker is thanked for his advice on the method used. Collin Simpfendorfer is thanked for comments on earlier results and Enric Cortés for discussions on the confidence interval estimation. Thanks are also given to Phillip Sanchez and Altagracia Landa for their assistance in field, as well as Tad Pfister from the Prescott Marine Station (University of Arizona) and the CICTUS (University of Sonora) for their help in the logistics. The referees are thanked for their comments. The present study was partially supported by each of the Lucile and Packard Foundation and Instituto Nacional de la Pesca of Mexico.

\section{References}

ANON. 2000. Anuario Estadístico de Pesca. SEMARNAP.

AU, D. W., and S. E. SMITH. 1997. A demographic method with population density compensation for estimating productivity and yield per recruit of the leopard shark (Triakis semifasciata). Can. J. Fish. Aquat. Sci., 49: 633-678.

CAILLIET, G. M. 1992. Demography of the central California population of the Leopard shark (Triakis semifasciata). Aust. J. Mar. Freshw. Res., 43: 183-193.

CARLSON, K. J., and E. CORTÉS. (2003). Gillnet selectivity of small coastal sharks off the southeastern United States. Fish. Res., 60: 405-414.

CORTÉS, E. 1998. Demographic analysis as an aid in shark stock assessment and management. Fish Res., 39: 199-208.

GARCÍA-CAUDILLO, J. M., M. A. CISNEROS-MATA, and A. BALMORI-RAMÍREZ. 2000. Performance of a bycatch reduction device in the shrimp fishery of the Gulf of California, México. Biol. Conserv., 92: 199-205.

GELMAN, A., J. B., CARLIN, H. S. STERN, and D. B. RUBIN. 1995. Bayesian Data Analysis. Chapman \& Hall. London. $526 \mathrm{p}$.

HUETER, R. E., G. M. CAILLIET, J. F. MÁRQUEZ-FARIAS, J. L. CASTILLO-GÉNIZ, and C. J. VILLAVICENCIOGARAYZAR. 2000. Artisanal fisheries for elasmobranchs in the Gulf of California: a multi-institutional project. American Elasmobranch Society. American Fisheries Society. 14-20 June 2000. La Paz, BCS (abstract).

KIRKWOOD G. P., and T. I. WALKER. 1986. Gill net mesh selectivities for gummy shark, Mustelus antarcticus Günter, taken in south-eastern Australian waters. Aust. J. Mar. Freshw. Res., 37: 689-697. 
MÁRQUEZ-FARIAS, J. F., J. TYMINSKI, R. E. HUETER, J. L. CASTILLO-GÉNIZ, and C. MURILLO-PÉREZ. 1999. Diversidad de elasmobranquios en Sonora estimado de una prospecci-n de la pesquería artesanal. Memorias I Simposium Internacional sobre el Mar de Cortés. 25-28 Mayo 1999. DICTUS. Hermosillo, Sonora, México (abstract in spanish).

MCLOUGHLIN K. J., and J. D. STEVENS. 1994. Gill net mesh selectivities for two species of commercial Carcharhinid sharks taken in Northern Australia. Aust. J. Mar. Freshw. Res., 45: 521-534.

MILLAR, R. B. 2000. Untangling the confusion surrounding the estimation of gillnet selectivity. Can. J. Fish. Aquat. Sci., 55: 1328-1337.

SIMPFENDORFER, C., and P. UNSWORTH. 1998. Gill net mesh selectivity of dusky sharks (Carcharhinus obscurus) and whiskery sharks (Furgaleus macki) from south-western
Australia. Mar. Freshw. Res., 49: 713-718.

SMINKEY, T. R., and J. A. MUSICK. 1996. Demographic analysis of the sandbar shark, Carcharhinus plumbeus, in the western North Atlantic. Fish. Bull., 94: 341-347.

VENZON, D. J., and S. H. MOOLGAVKAR. 1988. A method for computing profile-likelihood-based confidence intervals. Appl. Stat., 37: 87-94.

WALKER, T. I., B. L. TAYLOR, R. J. HUDSON, and J. P. COTTIER. 1998. The phenomenon of apparent change of growth rate in gummy shark (Mustelus antarcticus) harvested off Southern Australia. Fish. Res., 39: 139-163.

WALKER, T. I. 1997. School shark 1996, Stock Assessment Report, Southern Shark Fishery Assessment Group. (Australian Fisheries Management Authority: Canberra), 45 p.

1998. Can shark resources be harvested sustainably? A question revisited with a review of sharks fisheries. Mar. Freshw. Res., 49: 553-572. 